\title{
Polos, eixos e zonas: cidades e ordenamento territorial na Amazônia
}

\author{
Saint-Clair Cordeiro da Trindade Júnior ${ }^{1}$ e Welbson do Vale Madeira ${ }^{2}$
}

1 Geógrafo, Doutor em Geografia Humana pela Universidade de São Paulo, Pesquisador nível 1D do Conselho Nacional de Desenvolvimento Científico e Tecnológico. Sócio efetivo do Instituto Histórico e Geográfico do Pará, Professor Titular do Núcleo de Altos Estudos Amazônicos da Universidade Federal do Pará, Brasil. E-mail: stclair@ufpa.br

2 Doutor em Desenvolvimento Socioambiental pelo Núcleo de Altos Estudos Amazônicos da Universidade Federal do Pará. Professor do Departamento de Economia e do Programa de Pós-Graduação em Desenvolvimento Socioeconômico da Universidade Federal do Maranhão, Brasil. E-mail: welbsonmadeira@uol.com.br

RESUM 0: Uma fase de rápida ocupação do território foi inaugurada a partir da década de 1960 na Amazônia. A presença de empresários, especuladores e migrantes, mediados por ações intencionais do Estado, definiu uma nova forma de ocupação territorial para a região. As estratégias de ação se basearam em pelo menos três tipos principais de ordenamento do território. Não obstante a continuidade existente entre eles, expressam-se em diferentes geometrias do desenvolvimento: os pontos (polos de crescimento), as linhas (eixos de integração) e as zonas (zoneamento ecológico-ecomico). Considerando esses diferentes arranjos territoriais, 0 artigo busca considerar o papel assumido pelas cidades em cada uma dessas estratégias de desenvolvimento regional, de forma a mostrar mudanças e continuidades que se fazem presentes na história regional recentente da Amazônia.

Palavras-chaves: Região. Ordenamento Territorial. Cidades. Desenvolvimento regional. Amazônia.

Poles, axes and zones: cities and territorial planning in the Amazon region ABSTRACT: A phase of rapid occupation of the territory was inaugurated in the Amazon region from the 1960s. The presence of entrepreneurs, speculators, and migrants, mediated by intentional actions of the State, defined a new territorial order imposed for the region. In this process, action strategies tend to be based on at least three main types of land use planning, which despite the continuity between them, suggest different development geometries: the points (poles of growth), the lines (integration axes) and the zones (ecological-economic zoning). Considering these different territorial arrangements, the paper seeks to consider the role played by cities in each of these regional development strategies in order to show changes and continuities in the recent history of the Amazon region.

Keywords: Region. Territorial Planning. Cities. Regional Development Strategies. Amazon.

\section{INTRODUÇÃO}

Os principais planos de desenvolvimento regional propostos no Brasil a partir da segunda metade do século XX tiveram no território um elemento central de preocupação. De forma sucessiva, as políticas de ordenamento territorial levaram em conta três referências centrais: os polos de crescimento (até a década de 1980), os eixos de integração e desenvolvimento (a partir da segunda metade da década de 1990) e a 
articulação entre esses últimos e os zoneamentos ecológico-econômicos (a partir principalmente dos anos 2000).

Apesar das diferentes conjunturas, na Amazônia brasileira todas essas políticas de ordenamento territorial apresentaram rupturas entre si, mas também tiveram continuidades. A presente reflexão leva em conta esses pressupostos e argumenta-se que as diferentes formas por meio das quais se manifestaram as políticas de ordenamento territorial, igualmente, consideraram as cidades como importantes elementos de articulação regional e de estruturação do território, fazendo parte, portanto, das políticas em referência. Dessa forma, na perspectiva de refletir criticamente sobre as ações desenvolvimentistas na Amazônia, analisam-se as estratégias de desenvolvimento regional com ênfase nas materializações territoriais das mesmas, para, em seguida, discutir o papel das cidades nas diferentes propostas de ordenamento territorial.

\section{POLOS, EIXOS E ZONAS NAS POLÍTICAS DE ORDENAMENTO TERRITORIAL NA A- MAZÔNIA}

As políticas mais incisivas de desenvolvimento regional e suas consequentes formas de ordenamento territorial para a Amazônia passaram a ocorrer principalmente a partir da década de 1970, e comportam algumas periodizações. Para Kohlhepp (2002), por exemplo, desde essa década é possível distinguir seis fases:

$1{ }^{a}$. Estabelecida desde a primeira metade dos anos 1970, referenciou-se na noção de eixos de desenvolvimento, e caracterizou-se pela construção de grandes rodovias, como a Transamazônica, a Perimetral Norte, a Cuiabá-Santarém e a Cuiabá-Porto VeIho-Manaus;

2ª . Predominou entre 1974 até 1980 e foi assentada na noção de polos de crescimento, materializando-se principalmente no Programa de Polos Agropecuários e Agrominerais da Amazônia (POLAM AZÔNIA);

3a. Estabelecida nos primeiros anos da década de 1980, materializou-se em programas de desenvolvimento rural integrados, destacando-se o Programa Integrado de Desenvolvimento do Noroeste do Brasil (POLONOROESTE), que foi desenvolvido em torno da BR-364;

4a. Marca da década de 1980, traduziu-se principalmente em megaprojetos minerais e agropecuários, cabendo destaque ao Programa Grande Carajás (PGC);

5a. Configurada a partir do início da década de 1990, teve com uma de suas principais expressões o Programa Piloto Internacional para Conservação das Florestas Tropicais Brasileiras (PPG-7);

60. Estabelecida desde a segunda metade da década de 1990, foi assentada em Eixos Nacionais de Integração e Desenvolvimento (ENIDs) e materializada nos Programas Brasil em Ação e Avança Brasil.

Sem entrar em choque com Kohlhepp (2002), porém mais preocupados com aspectos espaciais do desenvolvimento, M ello e Théry (2001) identificam três fases, nas 
quais foram valorizados diferentes espaços. Na primeira, na década de 1970, consideram que houve centralidade das faixas rodoviárias e das zonas de programas especiais e de colonização; na segunda fase, na década de 1980, o destaque foram os polos de crescimento; na terceira, a partir da segunda metade da década de 1990, as políticas territoriais tiveram nos corredores de exportação uma das suas principais configurações espaciais.

Embora pertinente, a periodização proposta por Kohlhepp (2002) merece, pelo menos, uma ressalva. Na verdade, embora o PPG-7 tenha se tornado uma referência importante, não chegou a constituir exatamente uma fase de desenvolvimento regional. Por outro lado, em um aspecto que, em nosso entendimento, vale também para as análises de Mello e Théry (2001), uma nova fase pode efetivamente ser identificada a partir de 2003, na medida em que, a partir desse momento, os zoneamentos ecológico-econômicos (parcialmente inspirados no PPG-7) se tornaram as principais referências de planejamento.

Do ponto de vista teórico, as primeiras políticas de desenvolvimento regional na Amazônia foram influenciadas diretamente pela teoria ricardiana das vantagens comparativas em sua versão contemporânea, ou seja, a teoria de Heckscher-Ohlin (CARVALHO; SILVA, 2006); pela teoria da base de exportação (NORTH, 1977); e pela teoria dos polos de crescimento (PERROUX, 1961 e 1977; BOUDEVILLE, 1969). Na década de 1970, materializaram-se no II Plano de Desenvolvimento da Amazônia (II PDA) e no Programa de Polos Agropecuários e Agrominerais da Amazônia (POLAM AZÔNIA). No início da década de 1980 configuram-se em grandes projetos, como os relacionados ao Programa Grande Carajás (PGC).

Segundo o discurso do governo, o POLAM AZÔNIA foi "dirigido fundamentalmente à ocupação de espaços vazios e à utilização dos eixos viários" (SUDAM, 1976, p. 46). Como desdobramento deste programa, definiu-se a estruturação de polos agrominerais, madeireiros, agropecuários e agroindustriais em diversas sub-regiões da Amazônia (SUDAM, 1976). O PGC, por sua vez, seria voltado para aproveitar o potencial mineral (ferro, cobre, manganês, níquel, estanho, ouro e bauxita), o potencial hidrelétrico, o potencial florestal e o potencial territorial (SUDAM, 1976; BRASIL, 1981).

O principal projeto no PGC foi desenvolvido pela então Companhia Vale do Rio Doce (CVRD), e voltou-se para exportar minérios da Serra de Carajás (Pará), a partir do porto de Ponta da Madeira, em São Luís (Maranhão). Para ligar os dois pontos foi construída a Estrada de Ferro Carajás (EFC).

Em todos os planos e programas apresentados nas décadas de 1970 e 1980 argumentou-se que deveriam ser aproveitadas as vantagens comparativas da região, quanto à disponibilidade de recursos minerais, água e energia com baixo custo, favorecendo as atividades com potencial exportador. Neste caso, a avaliação era a de que "uma região pode se expandir como resultado do crescimento da demanda de seus bens de exportação existentes" (NORTH, 1977, p. 309). Articulando-se a estes aspectos, tam- 
bém foi central a pretensão de estabelecer polos de desenvolvimento em municípios tidos como estratégicos, considerando, assim, tais pontos como fundamentais para a irradiação do desenvolvimento. Uma síntese dessa estratégia de desenvolvimento, baseada na geometria dos polos, é apresentada no quadro 1.

Quadro 1 - Polos: estratégias de desenvolvimento

\begin{tabular}{|l|l|}
\hline \multicolumn{1}{|c|}{ ELEMENTOS } & \multicolumn{1}{c|}{ CARACTERIZAÇÃO } \\
\hline $\begin{array}{l}\text { Os termos do de- } \\
\text { senvolvimento }\end{array}$ & $\begin{array}{l}\text { Implantação de novos "objetos" espaciais de natureza econômica e infraestrutural. } \\
\text { Incentivo à mobilidade da mão de obra para fins de povoamento e de formação do } \\
\text { mercado de trabalho. } \\
\text { Rompimento da lógica do "arquipélago regional" e busca da articulação entre regi- } \\
\text { ôes. }\end{array}$ \\
\hline $\begin{array}{l}\text { As estratégias de } \\
\text { desenvolvimento }\end{array}$ & $\begin{array}{l}\text { Ativação de polos de crescimento, com núcleos dinamizados a partir de "atividades } \\
\text { motrizes". } \\
\text { Projetos de colonização rural associados a polos de crescimento, como parte de um } \\
\text { "efeito de arraste". } \\
\text { Ação intensiva de empresas capitalistas na exploração dos recursos da região. }\end{array}$ \\
\hline O Estado & $\begin{array}{l}\text { Agente provedor de infraestrutura. } \\
\text { Responsável pela criação de órgãos de planejamento, financiamento etc. } \\
\text { Concessão de incentivos/ subsídios fiscais/creditícios à grande propriedade rural e aos } \\
\text { fluxos de capital. }\end{array}$ \\
\hline
\end{tabular}

Elaboração: Saint-Clair Trindade Jr.

A crise fiscal do Estado brasileiro levou a um recuo nas políticas desenvolvimentistas ainda na década de 1980. Essa situação, por sua vez, contribuiu para que, na década seguinte, fosse argumentado que seria necessário aumentar a inserção do Brasil no mundo globalizado. Sob este argumento o Governo Fernando Henrique Cardoso (1995-2003) apresentou os Planos Plurianuais (PPAs) 1996-1999 e 2000-2003, denominados, respectivamente, Brasil em Ação e Avança Brasil (BRASIL, 1996; 2000). Diferentemente dos planos anteriores, estes foram centrados em Eixos Nacionais de Integração e Desenvolvimento (ENIDs).

Os ENIDs foram apresentados como uma política de divisão territorial em função de projetos considerados estratégicos pelo governo, buscando-se adaptar o Brasil à globalização e estimular o crescimento da economia (BRASIL, 1996; 2000; ACSELRAD, 2001). De um total de dez eixos nacionais, três teriam ligações diretas com a Amazônia: o Eixo Araguaia-Tocantins, o Eixo Madeira-Amazonas e o Eixo Arco Norte.

Nos três eixos que abarcaram a Amazônia, a maior parte dos projetos destinou-se a recuperar rodovias e hidrovias existentes ou construir infraestruturas apontadas como estratégicas. No primeiro grupo, destaca-se a restauração das rodovias BelémBrasília e M arabá-São Geraldo; a pavimentação da BR-174, entre Manaus (AM) e Caracaraí (RO); a pavimentação da BR-401, entre Boa Vista (RR) e Bonfim (RR), na fronteira com a Guiana; a recuperação da BR-317, entre Rio Branco (AC) e Assis Brasil (AC), na fronteira com o Peru; e a melhoria da hidrovia do Rio Madeira. No segundo grupo, destacam-se as construções da hidrovia do eixo Araguaia-Tocantins e das usinas hidrelétricas de Santo Antônio e Jirau, no Rio Madeira; e de Belo Monte, no Rio 
Xingu (BRASIL, 2000). No início dos anos 2000, Mello e Théry já consideravam que esse tipo de política poderia "alterar sensivelmente a organização do espaço amazônico, criando novos eixos de circulação no sentido norte-sul, que atravessam a Amazônia, ligando-a não só ao sul do Brasil, mas também ao norte do continente" (M ELLO; THÉRY, 2001, p. 186).

Referindo-se especificamente ao Avança Brasil, Becker avaliou que os ENIDs fundamentaram-se "em objetivos logísticos nacionais, sem levar em conta as estratégias regionais de inserção na estrutura produtiva nacional e na economia global" (BECKER, 2006, p. 133). Na mesma linha, Serra e Fernández (2004), entendem que a lógica associada aos eixos é de que "a competitividade nos mercados nacional e internacional depende fundamentalmente da capacidade de transportar consideráveis volumes de mercadoria a longas distâncias com velocidade e eficiência" (SERRA; FERNÁNDEZ, 2004, p. 123). Importa, diante disso, considerar que uma nova geometria de desenvolvimento regional começou a se apresentar, pautada nos eixos de modernização econômica e territorial, cujo perfil é apresentado sinteticamente no quadro 2.

Quadro 2 - Eixos: estratégias de desenvolvimento

\begin{tabular}{|l|l|}
\hline \multicolumn{1}{|c|}{ ELEMENTOS } & \multicolumn{1}{c|}{ CARACTERIZAÇÃo } \\
\hline $\begin{array}{l}\text { Os termos do de- } \\
\text { senvolvimento }\end{array}$ & $\begin{array}{l}\text { Oposição discursiva ao nacional-desenvolvimentismo, de caráter intervencionista, da } \\
\text { década anterior. } \\
\text { Prioridade ao comércio exportador, com inserção competitiva do País nos circuitos } \\
\text { globais. } \\
\text { Integração regional e interiorização com vistas à definição de novas fronteiras de } \\
\text { desenvolvimento. }\end{array}$ \\
\hline $\begin{array}{l}\text { As estratégias de } \\
\text { desenvolvimento }\end{array}$ & $\begin{array}{l}\text { Baseadas em "corredores de exportação", com perspectivas de inovação assentadas } \\
\text { em eixos e fluxos de bens/serviços. } \\
\text { Racionalização/aproveitamento de cadeias produtivas em potencial, situadas nas } \\
\text { áreas de influência dos eixos. } \\
\text { Planejamento integrado de natureza não setorial (sinergia entre setores econômicos). }\end{array}$ \\
\hline Estado & $\begin{array}{l}\text { Voltado para ações neoliberais de desenvolvimento regional, com o papel de remo- } \\
\text { ver obstáculos, abrir horizontes de investimentos e favorecer a desconcentração e- } \\
\text { conômica e territorial. } \\
\text { Adoção de uma concepção estratégica de desenvolvimento, com otimização sistêmi- } \\
\text { ca, exploração de oportunidades e geração de efeitos multiplicadores. } \\
\text { Ações consorciadas e de parceria com a iniciativa privada. }\end{array}$ \\
\hline
\end{tabular}

Fonte: Ablas (2003), Galvão e Brandão (2003) e Leitão (2009).

Elaboração: Saint-Clair Trindade Jr.

Nos ENIDs foram priorizados projetos voltados para a exportação, e as questões ambientais e sociais foram tratadas como apêndices (EGLER, 1999; NASSER, 2000; NEPSTAD et alii, 2000). E foi diante deste cenário que, a partir de 2003, os governos passaram a afirmar que iniciariam um modelo de desenvolvimento sustentável (OLIVA, 2010). Referindo-se a essa possibilidade, avaliou-se à época:

o país poderá ampliar suas vantagens comparativas na economia mundial, se nos próximos anos continuar a incorporar a sustentabilidade ambiental 
como parte fundamental da estratégia de consolidação do Novo Desenvolvimentismo brasileiro (OLIVA, 2010, p. 397).

Segundo os governos Lula (2003-2010) e Dilma (2011-2016), seria possível conciliar objetivos que foram pretendidos com os ENIDs à preservação ambiental e respeito aos direitos de populações tradicionais. Assim, em 2008 foi apresentado o Plano Amazônia Sustentável (PAS), e em 2010 o Macrozoneamento Ecológico-Econômico da Amazônia Legal (MacroZEE). Em ambas as iniciativas argumentou-se que as estratégias anteriores levaram a Amazônia a uma progressiva articulação a outras escalas geográficas, e que se fazia necessária a "revisão do conceito de organização do espaço geográfico e das bases conceituais e metodológicas que a referenciam" (BRASIL, 2010, p. 7).

O PAS trouxe como objetivos declarados consolidar o modelo de desenvolvimento sustentável, combater os processos de degradação ambiental e estabelecer diretrizes para o ordenamento territorial e a gestão ambiental (BRASIL, 2008). O M acroZEE, por seu turno, deveria acelerar a transição do modelo anterior para uma estratégia de desenvolvimento sustentável, favorecendo a harmonia entre atividades produtivas e políticas de conservação ambiental. Nessa perspectiva, foram estruturadas unidades territoriais denominadas territórios-rede, territórios-fronteira e territórios-zona (BRASIL, 2010).

Dos territórios-rede constam o corredor de integração Amazônia-Caribe, as capitais costeiras, a mineração e outras cadeias produtivas, assim como, o entroncamento Pará-Tocantins-Maranhão, o eixo Araguaia-Tocantins, o complexo agroindustrial e o polo logístico de integração com o Pacífico. Dos territórios-fronteira faz parte a fronteira agroflorestal e pecuária e as frentes de expansão. Por fim, como territórioszona, constam o que é denominado de coração florestal e o pantanal de M ato Grosso (BRASIL, 2010).

Das dez unidades territoriais, apenas as pertencentes aos territórios-zona aparentemente priorizam a dimensão ecológica do zoneamento. Enquanto isso, os territórios-rede e os territórios-fronteira constituem-se explicitamente espaços para projetos voltados para exportações, originados nos programas Brasil em Ação e Avança Brasil e ratificados nos Programas de Aceleração do Crescimento (PAC) dos Governos Lula da Silva e Dilma Rousseff. Assim, não obstante as continuidades, outros elementos foram acrescentados na nova geometria do desenvolvimento (quadro 3 ).

Quadro 3 - Zonas: estratégias de desenvolvimento

\begin{tabular}{|c|c|}
\hline ELEMENTOS & CARACTERIZAÇÃO \\
\hline $\begin{array}{l}\text { Os termos do de- } \\
\text { senvolvimento }\end{array}$ & $\begin{array}{l}\text { Convivência de uma economia de fronteira com um vetor tecnoecológico de desen- } \\
\text { volvimento. } \\
\text { Integração amazônica como parte de um projeto nacional de inserção no atual está- } \\
\text { gio da globalização. } \\
\text { Discurso de um desenvolvimento econômico sustentável. } \\
\text { Busca por uma possível integração das dimensões econômica, social e ambiental do } \\
\text { desenvolvimento. }\end{array}$ \\
\hline
\end{tabular}




\begin{tabular}{|l|l|}
\hline $\begin{array}{l}\text { As estratégias de } \\
\text { desenvolvimento }\end{array}$ & $\begin{array}{l}\text { A ambientalista/preservacionista: mais articuladas aos movimentos ambientais. } \\
\text { A geopolítica ecológica: mais associadas às estratégias das empresas. } \\
\text { Os projetos alternativos de desenvolvimento/conservação: mais ligados a agentes } \\
\text { extrativistas e pequenos produtores da região. }\end{array}$ \\
\hline O Estado & $\begin{array}{l}\text { Agente mediador /orquestrador de diferentes interfaces entre o público e o privado. } \\
\text { Responsável por integração de projetos/programas e parcerias transescalares, envol- } \\
\text { vendo instituições governamentais e sociedade civil. } \\
\text { Retóricas e práticas em torno da participação e da gestão compartilhada. }\end{array}$ \\
\hline
\end{tabular}

Fonte: Becker (1997) e Mello (2006).

Elaboração: Saint-Clair Trindade Jr.

A partir dessa forma de ordenamento definiu-se a configuração de uma malha territorial mais complexa, que acrescenta de maneira mais enfática a preocupação de natureza socioambiental, como as Terras Indígenas (TIS), as Unidades de Conservação (UCs), os Territórios da Cidadania (TCS), dentre outros.

Não se trata, entretanto, de uma nova malha socioespacial que nega a anterior, que foi herdada de outros momentos. Conforme Becker (2006), ao vetor técnicoindustrial, do passado, acrescenta-se e sobrepõe-se outro, o vetor tecnoecológico, que se preocupa com a biodiversidade, com a sociodiversidade e com o desenvolvimento sustentável. Daí, conforme sugere a mesma autora, coloca-se a possibilidade de reconhecer a formação de sub-regiões na Amazônia com potencialidades diversas, inclusive como forma de subsidiar políticas de gestão territorial e ambiental e de desenvolvimento econômico.

Isso nos permite concluir que as estratégias de desenvolvimento baseadas em polos de crescimento, em eixos de integração e em zoneamentos econômicos e ecológicos têm em comum, ainda que com variações, dinâmicas de produção capitalista do espaço que resultam ainda na tendência de um desenvolvimento geográfico desigual. Nessas dinâmicas, as cidades assumem papeis centrais, e, por isso, merecem ser destacados.

\section{AS CIDADES: IM PORTÂNCIA EM FACE DOS POLOS, DOS EIXOS E DAS ZONAS}

A concepção de cidades como condição de ordenamento do território não é, de fato, algo recente na dinâmica da Amazônia. Outros exemplos podem ser mencionados na história regional, como os relacionados à política pombalina, ao urbanismo do arquiteto italiano Antônio Landi e ao plantio racional da borracha de Henri Ford, mas é principalmente por meio das políticas de desenvolvimento regional, desencadeadas a partir da segunda metade do século XX, que uma urbanização mais sistemática começa a se tornar mais clara.

É assim que a partir da década de 1960 um processo de urbanização de natureza mais difusa começou a se verificar no reordenamento territorial amazônico, passando a integrar estratégias de desenvolvimento regional de forma mais incisiva. Tais estratégias assentavam-se nas três principais formas ou geometrias de ordenamento do território já mencionadas. 
Em relação à primeira dessas expressões de ordenamento territorial, a geometria punctiforme do desenvolvimento pautou-se nos pontos de investimentos e de incentivos fiscais e creditícios que seriam irradiadores de modernização e de desenvolvimento. É nesse sentido que a "armature regional" pressupôs, conforme Becker (1990), uma rede técnico-política de integração, a superposição de territórios federais sobre os estaduais e, nos termos de Porto-Gonçalves (2001), um padrão rodovia/terra firme/subsolo de ocupação territorial.

Foi a partir desse modelo que se configurou no território amazônico a ideia de regiões polarizadas, consideradas espaços definidos por pontos e áreas de influência, que deveriam ser coerente e coesamente estruturados através de fluxos e interações (de mercadorias, de pessoas e de informações). Para a configuração dessas regiões, os núcleos e as aglomerações urbanas deveriam assumir o papel de bases logísticas de ocupação do território, pontos importante de distribuição da força de trabalho e centros de apoio à colonização e à implantação de grandes projetos (BECKER, 1990).

Dentre as expressões que se associam a esse processo, pode-se destacar o modelo de "urbanismo rural", em que as agrovilas, as agrópolis e as rurópolis (quadro 4) articuladas às estratégias de colonização oficial, por meio do Instituto Nacional de Colonização e Reforma Agrária (INCRA) ou, mesmo, de companhias privadas de colonização agrária, assumiam papel importante nas estratégias de desenvolvimento regional. Ainda que pensadas para ser estabelecidas ao longo dos eixos das estradas, sem dúvida, trata-se de um modelo que se articulou aos projetos econômicos difusos que se tornaram presentes na região nos anos seguintes.

Quadro 4 - Modelo de "Urbanismo Rural"

\begin{tabular}{|l|l|}
\hline LOCALIDADES & \multicolumn{1}{c|}{ FUNÇÕES } \\
\hline Agrovilas & $\begin{array}{l}\text { Pequenos centros urbanos para moradia de trabalhadores rurais. } \\
\text { Integração de habitantes do meio rural sugerindo-Ihes "condições de vida em moldes civili- } \\
\text { zados". } \\
\text { Modelo de Bairro Rural: lotes rurais (mais voltados para o trabalho) e urbanos (mais volta- } \\
\text { dos para a moradia). } \\
\text { Lote urbano com pomar, horta, pequenos criatórios etc. para proprietários de lotes rurais e } \\
\text { para empregados rurais. } \\
\text { Lote rural: produção agrícola/ pastoril e moradia. }\end{array}$ \\
\hline Agrópolis & $\begin{array}{l}\text { Pequenos centros urbanos agroindustriais, culturais e administrativos. } \\
\text { Apoio à integração social do meio rural. } \\
\text { Influência socioeconômica, cultural e administrativa num raio de aproximadamente 10 km. } \\
\text { Polarização de 8 a 10 agrovilas. }\end{array}$ \\
\hline Rurópolis & $\begin{array}{l}\text { Pequenos polos de desenvolvimento. } \\
\text { Centro principal de uma grande comunidade rural hierarquizada por núcleos menores. } \\
\text { Polarização de agrópolis e agrovilas - 70 a 140 km de raio. } \\
\text { Núcleo urbano-rural: diversificação de atividades (públicas/privadas) de interesse local e de } \\
\text { sua área de influência. } \\
\text { Atividades: comércio, indústria, serviços (sociais, culturais, religiosos, médico- } \\
\text { odontológico, administrativos). } \\
\text { Combinação: rural-urbano, agricultura-indústria, produção-comércio. }\end{array}$ \\
\hline
\end{tabular}

Fonte: INCRA (1973, p. 14,16-17 apud IANNI, 1979, p. 61).

Elaboração: Saint-Clair Trindade Jr. 
Associadas ao modelo rodoviário, mas também ao dinamismo de determinados polos de crescimento pensados para o espaço regional, tais cidades acabaram por atrair mão de obra móvel e polivalente e muitas vezes não especializada, de origem cultural diversa e, normalmente, de pouca identidade com o ambiente da floresta, 0 que também contribuiu para a forte pressão sobre o meio ambiente, ratificada pelas políticas de pouco ou nenhum apoio aos pequenos produtores. Alguns desses núcleos, mesmo não tendo cumprido as funções e o papéis incialmente concebidos para eles, tornaram-se, posteriormente, pequenas cidades, sedes de novos municípios, surgidos em consequência desse processo de produção do espaço regional e do novo ordenamento regional imposto a partir das políticas oficiais.

Uma das melhores expressões da urbanização associada a essa estratégia de desenvolvimento, entretanto, apoia-se na ideia de polos de crescimento, concebidos com base na difusão da modernização e do crescimento econômico a partir de uma espécie de "efeito de arraste" a ser proporcionado por meio de atividades econômicas que revelam os potenciais locais e sub-regionais presentes no espaço amazônico.

Na mesma ideia também foram inspiradas as novas cidades planejadas e que buscavam viabilizar grandes interesses corporativos, normalmente associados aos grandes projetos. Concebidas discursivamente sob modelos de interações diferenciados cidades fechadas, cidades semifechadas e cidades abertas (quadro 5) -, tais núcleos urbanos cumpriam papeis logísticos importantes com vistas ao funcionamento de diferentes projetos extrativistas, a exemplo da exploração mineral; da transformação primária de matéria-prima, como no caso da bauxita e da alumina; ou de implantação de infraestrutura, como pode se observado na implantação de usinas para a produção de energia elétrica. Essa proposta de cidades modernas e dotadas de infraestrutura mais avançada tornou-se um modelo de um urbanismo de enclave, de pouca troca favorável à população do entorno e de clara conexão com espaços extra locais, em que pese 0 discurso de interação e de atendimento das demandas regionais.

Quadro 5 - Cidades das empresas

\begin{tabular}{|l|l|l|l|}
\hline \multicolumn{1}{|c|}{ CIDADES } & \multicolumn{1}{|c|}{ NATUREZA } & \multicolumn{1}{c|}{ CONTROLE } & EXEM PLO \\
\hline Fechadas & $\begin{array}{l}\text { Projetadas pela empresa como } \\
\text { base logística de seus empreen- } \\
\text { dimentos. }\end{array}$ & $\begin{array}{l}\text { Interdição, controle e } \\
\text { vigilância rígidos. }\end{array}$ & Carajás (PA) \\
\hline Semiabertas & $\begin{array}{l}\text { Projetadas pela empresa como } \\
\text { base logística do empreendimen- } \\
\text { to e base complementar para 0 } \\
\text { entorno. }\end{array}$ & $\begin{array}{l}\text { Maior interação com o } \\
\text { entorno. }\end{array}$ & Tucuruí (PA) \\
\hline Abertas & $\begin{array}{l}\text { Projetadas pelas empresas e pelo } \\
\text { Estado para serem polos regio- } \\
\text { nais. }\end{array}$ & $\begin{array}{l}\text { Menor controle, com ofer- } \\
\text { ta de serviços para o en- } \\
\text { torno. }\end{array}$ & $\begin{array}{l}\text { Vila dos Cabanos } \\
\text { (PA) }\end{array}$ \\
\hline
\end{tabular}

Elaboração: Saint-Clair Trindade Jr. 
De qualquer forma, independentemente do discurso que the atribuem diferenças, identificam um novo padrão de desenvolvimento e de urbanismo para a região, seja por abrigarem uma mão de obra especializada, seja também por exercem forte pressão sobre 0 ambiente da floresta em dois sentidos. 0 primeiro, em razão da lógica que preside o surgimento desse tipo de cidade, que tem relação com formas diversas de exploração de recursos ligados aos circuitos globais, como a exploração do minério de ferro, da bauxita e da água para a produção de energia elétrica; todos, normalmente, de fortes impactos locais e regionais. 0 segundo, em razão do valor simbólico e cultural, que remete à ideia de estranhamento/deslocamento dessas cidades e de seus conteúdos em relação à história local e às vivências cotidianas e aos espaços pré-existentes.

Na nova lógica de desenvolvimento regional assentada em corredores de desenvolvimento, esse tipo de cidades já não assume importância na forma inicial em que foram concebidas. Diferentemente de décadas anteriores, há novas maneiras de difusão do urbano na região, que se diferem daquelas outras inspiradas no desenvolvimento intervencionista das primeiras décadas de integração regional. Nesse contexto, a rede urbana se apresenta menos rígida do ponto de vista hierárquico, estabelecendo curtos-circuitos e conexões diversas e difusas.

Isso permite conferir destaque a novos centros urbanos de natureza sub-regional, normalmente de porte intermediário, que são importantes "nós" de fluxos de bens e serviços diversos, como aqueles que potencializam a biodiversidade e o ecoturismo, mas com destaque principalmente àqueles relacionados aos agronegócios, à mineração e à produção de energia elétrica. Exemplos destes últimos, respectivamente, é a cidade de Açailândia, no Maranhão e de Santarém (Baixo Amazonas), entrepostos de escoamento da soja; Marabá (Sudeste do Pará), base importante para a definição do circuito do ferro; e Altamira (Sudoeste do Pará), núcleo principal de apoio ao empreendimento hidrelétrico de Belo M onte.

Cidades como essas assumem papel logístico de importância estratégica, no sentido de estabelecer conexões a diferentes modais de transporte e de redes de comunicação, e cuja infraestrutura, comércio e serviços instalados são concebidos para atender a demandas corporativas ligadas a produtos de grande aceitação nos mercados nacionais e globais e que, por esse motivo, também exercem relativa pressão no ambiente da floresta.

Pela importância que têm essas cidades de natureza intermediária, assim como outras pequenas cidades situadas nesses corredores ou por ele influenciadas direta e indiretamente, há uma mudança substancial nos seus conteúdos urbanos. Não se trata mais das cidades dos notáveis, à maneira como se referiu Santos (1993) para se referir às cidades do passado, mas principalmente de cidades econômicas, conforme denominou o mesmo autor as cidades cuja dinâmica está diretamente associada às novas demandas econômicas modernas que acontecem no entorno e que as articulam muitas vezes a circuitos e mercados mais distantes. Nelas, os personagens mais 
importantes não são mais o padre, o juiz, a professora primária, dentre outros, mas 0 engenheiro agrônomo, o veterinário, o empresário do provedor de internet, o gerente do banco etc., todos agentes ligados à modernização capitalista.

É por essa razão que, dentre os novos conteúdos que fazem parte da nova cena urbana, incluem-se a presença cada vez maior de concessionárias de veículos automotores, a proliferação de agências bancárias, a difusão de lojas comerciais e de serviços voltadas para os agronegócios, 0 aumento de franquias nacionais e internacionais, assim como a inserção de grandes equipamentos de difusão de consumo que integram um circuito moderno da economia urbana, como as lojas de departamentos e os shoppings centers, que hoje já se fazem presentes nas cidades médias da Amazônia.

Afora os atributos econômicos, entretanto, outras formas de centralidades conferem importância a esses pontos nodais do espaço amazônico. É o que acontece com a centralidade de natureza política, por meio da qual se verifica a presença de instituições e órgãos oficiais (estaduais e federais) ligados às diversas formas de gestão e de decisão política, assim como a presença de importantes associações, representações de classe, sindicais e categorias sociais diversas que conferem centralidade às forças políticas locais e sub-regionais que, a partir dessas cidades, ganham projeção, inclusive dando visibilidade a movimentos que propõem a criação de novas unidades da federação, seja na forma de novos estados, seja na forma de novos municípios.

E para a concepção mais recente de ordenamento territorial que se tem desenhado a partir dos zoneamentos ecológico-econômicos, quais têm sido os papéis que se projetam para os núcleos urbanos?

Ainda que o processo de urbanização hoje não seja o mesmo daquele que se apresentou nos primeiros momentos de formação da fronteira econômica, ele não deixou de ser importante na constituição da fronteira tecnoecológica, nos termos propostos por Becker (2006). É dessa forma que essa mesma autora chama atenção para o papel atual das cidades na Amazônia, uma vez que, além de concentrarem milhões de consumidores, são sedes das instituições políticas públicas e privadas, oferecem alternativa de emprego e renda, barrando a migração para a floresta, sendo base em potencial para o beneficiamento local de produtos do seu entorno, assim como, centros de distribuição de serviços para as populações de UCs, Tls etc. Constituem-se também, ainda segundo Becker (2006), importantes referências para os assentamentos da reforma agrária nas áreas a serem recuperadas e possuem papel logístico na conexão de diferentes modais de transporte e redes de comunicação; condições essas que lhes dão o papel de relays da unidade regional.

Nesse sentido, da mesma forma que os novos modelos de ordenamento não representam negação dos anteriores, os papeis das cidades parecem ser reforçados a cada novo momento de reconfiguração territorial, ratificando uma urbanização difusa que se ajusta às novas demandas sem necessariamente representar tensões muito fortes entre um modelo de cidade mais voltado para as novas demandas de mercado 
e outro mais alternativo, que poderia sugerir uma concepção mais cívica e cidadã de ordenamento territorial, no sentido proposto por Santos (1987).

Esse ajuste do território às novas demandas de acumulação capitalista é bem interpretada por Harvey (2004) quando mostra que "a produção e a reconfiguração de relações espaciais oferecem um forte meio de atenuar, se não resolver, a tendência de formação de crises no âmbito do capitalismo" (HARVEY, 2004, p. 78). Para o autor, aliás, "foi principalmente com o deslocamento espacial e temporal que o regime fordista de acumulação resolveu o problema da superacumulação no decorrer do longo período de expansão do pós-guerra" (HARVEY, 2010, p. 173). Nesta efetiva produção de espaço, a intervenção do Estado se tornou decisiva, na medida em que

a capacidade tanto do capital como da força de trabalho de se moverem, rapidamente e a baixo custo, de lugar para lugar, depende da criação de infraestruturas físicas e sociais fixas, seguras e, em grande medida, inalteráveis. A capacidade de dominar o espaço implica na produção de espaço (HARVEY, 2006, p. 147).

Uma das bases dessa argumentação se remete à "lei do desenvolvimento desigual e combinado", discutida por Smith (1988) no seu propósito de refletir sobre as diferenças e desigualdades espaciais. Referindo-se também a ela, Corrêa (1991) destaca que a mesma "traduz-se (...) no processo de regionalização que diferencia não só países entre si como, em cada um deles, suas partes componentes, originando regiões desigualmente desenvolvidas, mas articuladas" (CORRÊA, 1991, p. 45).

Como referência de continuidade entre as estratégias de desenvolvimento econômico na Amazônia, verifica-se que a noção institucionalizada de desenvolvimento sustentável revela-se, muitas vezes, compatível com novas formas arrojadas de produção capitalista de espaço e aponta mesmo para a manutenção de um desenvolvimento desigual. Há um provável novo ciclo de expansão da "economia de fronteira", que pode ser verificado, por exemplo, em áreas de conservação e em terras indígenas e que está a serviço principalmente de grupos que se consolidaram a partir de políticas de estímulo à formação e à definição de mercados e de circuitos nacionais e globais de interesses capitalistas.

Os modelos e estratégias de desenvolvimento parecem assim não serem excludentes, sugerindo mudanças nas geometrias do desenvolvimento (polos, eixos e zonas) que renovam o discurso desenvolvimentista, mas que não propõem de fato uma nova geografia do desenvolvimento regional. Conforme nos mostra M adeira (2015), em seu estudo sobre o corredor da Estrada de Ferro Carajás, as cidades e municípios diretamente cortados ou influenciados por essa ferrovia, na parte oriental da Amazônia, tiveram nas intervenções estatais, pautadas discursivamente em um novo ordenamento do território, uma forma de se ajustar a sucessivas estratégias de controle territorial: Programa Grande Carajás (PGC), Programas Brasil em Ação e Avança Brasil, Programa de Aceleração de Crescimento e Plano Amazônia Sustentável. 
Essas estratégias demonstram, em grande medida, uma continuidade a processos de intervenção territorial com grande impacto local e regional, que se iniciaram ou foram concebidos ainda sob a ideia dos polos de crescimento, reforçaram-se na perspectiva dos eixos de desenvolvimento e, mais recentemente, parecem se ajustar a uma ordem territorial que tem como premissa o discurso do zoneamento econômico e ambiental e do desenvolvimento sustentável, sem que, para isso, coloque-se em curso uma real alternativa de negação do grau de influência do setor empresarial na determinação dos rumos dos acontecimentos no plano regional, local e sub-regional.

\section{CONSIDERAÇÕES FINAIS}

Brandão (2007) aponta que "a análise crítica do movimento desigual da acumulação do capital no espaço requer a verificação articulada dos processos de homogeneização, de integração, de polarização e de hegemonia nos recortes territoriais" (BRANDÃO, 2007, p. 70). A primeira diz respeito às condições de reprodução do capital em geral, e tem como resultado o espaço unificado para a valorização do capital. Por integração, 0 autor destaca como as diversas frações do capital ocupam os espaços e se articulam nessa dinâmica. A polarização, por sua vez, implica em hierarquias, e é determinada pela "natureza desigual e combinada do processo de desenvolvimento" (BRANDÃO, 2007, p.81). Por fim, com a noção de hegemonia, 0 autor ressalta a importância da correlação de forças sociais e políticas.

Os discursos que propõem novas formas de desenvolvimento parecem apostar na organização das formas e dos objetos espaciais como potencializadores do desenvolvimento, não problematizando a questão do desenvolvimento desigual de que são portadoras as diferentes estratégias de reprodução capitalista, sempre articuladas a interesses de agentes hegemônicos que se articulam em diferentes escalas do espaço, notadamente aquelas que se apresentam além dos espaços locais e sub-regionais.

É nesse sentido que Santos (1980) destaca que "a reorganização de um subespaço sob a influência de forças externas depende sempre do papel que o Estado exerce", e este aparece como "fator por excelência de elaboração do espaço" (SANTOS, 1980, p. 183). 0 autor entende que as modernizações na fase contemporânea expressam-se em novas atividades ou em adaptações de atividades pré-existentes, e "o fato de que os espaços não são alcançados igualmente por todas as modernizações induz ao critério da diferenciação entre os países" (SANTOS, 2008, p. 48).

A ênfase ao "sistema de objetos" e à forma espacial em detrimento da multidimensionalidade (econômica, política, social, ambiental e cultural) dos "sistemas de ações", sugere repensar o modelo de ordenamento territorial assentado em perspectivas que atendam a demandas e a interesses econômicos e políticos, substituindo-o por outro com uma preocupação de_natureza cívica, que atenda a demandas mais cidadãs (SANTOS, 1987). 
E é nesse sentido que Santos (1987) sustenta, na articulação dialética que estabelece entre espaço e cidadania, uma forma cívica de ordenamento territorial, como contraponto aos modelos econômicos e políticos de espaço, dominantes no Brasil. A respeito do modelo econômico, argumenta:

um modelo econômico, tomado isoladamente, e por melhor que ele pareça, não bastará para que os grandes problemas da nação sejam solucionados. A sociedade é mais que a economia. Um modelo que apenas se ocupe da produção em si mesma (ainda que as diversas instâncias produtivas estejam incluídas: circulação, distribuição, consumo), nem mesmo para a economia será operacional. A sociedade também é ideologia, cultura, religião, instituições e organizações formais e informais, território, todas essas entidades sendo forças ativas. 0 econômico pode parecer independente em seu movimento, mas não o é. A interferência das demais entidades que formam o corpo da nação corrige ou deforma ou, simplesmente, modifica as intenções do planejamento econômico, sobrepondo-lhe a realidade social (SANTOS, 1987, p. 95-96).

Em acréscimo, o mesmo autor argumenta em relação ao modelo político:

é do modelo político, considerado como abrangente de todas as ações que se dão num território... que se deveria ou poderia esperar um tratamento sintético dessas variáveis interdependentes, com a formulação de projetos de nação... Como a vida política mantém sua própria lógica e os partidos são instituições reais, institucionaliza-se um estado de coisas incapaz de levar a mudanças positivas, já que a tão buscada representatividade se torna cada vez mais distante de ser atingida (SANTOS, 1987, p. 96-97).

Como alternativa, sugere um modelo cívico de ordenamento territorial:

mudar o modelo econômico, ou o modelo político, tal como é praticado, de nada valerá se um novo modelo cívico não se instala....Todo nosso esforço deve estar empenhado na codificação desse modelo cívico, não mais subordinado ao modelo econômico, como até agora se deu, mas um modelo cívico que oriente a ação política e alicerce a solidariedade social e ao qual o modelo econômico e todos os demais modelos sejam subordinados (SANTOS, 1987, p. 99-100).

O que nos é apresentado como modelo cívico de ordenamento territorial pelo autor em referência nos ajuda a pensar o papel que as cidades têm assumido na Amazônia a cada momento que o território é concebido como sendo parte de uma nova estratégia de desenvolvimento regional avalizada pelo Estado; ora mais interventor, ora mais sinalizador, e outras vezes como mediador e parceiro de interesses de agentes econômicos e políticos hegemônicos. 
Associada a ideia de modelo cívico de espaço, proposta por Santos (1987), parece igualmente interessante vislumbrar alternativas de articulação espacial e funcional da região que a coloquem em outra perspectiva que, muito mais que reforçar o papel das cidades como nós estratégicos de um desenvolvimento geográfico desigual, definam centralidades de natureza mais cívica, voltadas paras demandas que não sejam hegemonicamente corporativas, conforme sugerem Huffmann et alii (2016).

Ao propor as "centralidades cívicas" para o nível intraurbano, esses autores colocam como sendo indispensável uma estruturação espacial produzida mediante uma rede de nós articulados territorialmente, capazes de constituir, por sua vez, instrumentos preocupados a redensificar determinadas áreas. Ao mesmo tempo, tendem a definir e/ou reforçar subcentralidades pré-existentes com critérios de inclusão de usos e funções diversos, que, capitalizando a rede de transporte notadamente público, possam favorecer a acessibilidade, bem como, promover "peças urbanas polifuncionais" em diferentes porções do espaço.

O mesmo tipo de centralidade, imaginada para o nível intraurbano, torna-se válido também para o nível sub-regional, posto que toda centralidade cívica é concebida como ferramenta de articulação espacial e funcional do tecido espacial. Para além de concepções nodais, concebem-se redes articuladas não apenas em funções administrativas, mas incorporando demandas mais amplas, relacionadas com necessidades sociais e territoriais mais prementes da cidade (HUFFM ANN et alii, 2016) e, no caso aqui considerado, de seu entorno imediato e mediato.

Corroborando com essa perspectiva apontada pelos autores, a noção de cidade de "responsabilidade territorial", proposta por Bitoun (2009), e recorrente também nos trabalhos sobre a Amazônia ocidental elaborados pelos pesquisadores do Núcleo de Estudos e Pesquisas das Cidades da Amazônia Brasileira (NEPECAB), da Universidade Federal do Amazonas, situa, igualmente, o papel das cidades para além de sua natureza corporativa e dos interesses políticos hegemônicos que nelas e por meio delas se espacializam, notadamente em realidades regionais mais empobrecidas e distantes dos principais centros econômicos brasileiros, onde as densidades técnicas e de modernização do território são pontuais ou ainda não se fazem tão marcantes nas paisagens locais e sub-regionais:

algumas cidades brasileiras... são, pela distância que as separam de quaisquer outras cidades, os únicos recursos "urbanos" para populações dispersas em grandes espaços do Brasil central e ocidental. Segundo a equipe do Observatório Pernambuco, a Política Nacional de Desenvolvimento Urbano precisava considerar essas cidades importantes, independentemente do seu tamanho populacional e funcional, exatamente pela falta de alternativas para as populações circunvizinhas... A política urbana deveria adaptar-se dando resposta ao urbano disperso e isolado presente no Brasil central e ocidental. Precisava considerar que, por falta de alternativas, essas cidades exerciam uma "responsabilidade territorial" peculiar (BITOUN, 2009, p. 32). 
"Responsabilidade territorial" (BITOUN, 2009), "modelo cívico de território" (SANTOS, 1987) e "centralidades cívicas" (HUFFM ANN et alii, 2015), ajudam a pensar, assim, uma concepção menos corporativa de território e, em potencial, mais voltada para a construção de uma ordem espacial e territorial onde a cidadania apareçam como uma importante variável na estruturação dos objetos e das ações que dão sentido às dinâmicas dos espaços.

Tais formas de pensar o território, se não vão necessariamente de encontro aos modelos que reforçam o desenvolvimento geográfico desigual, pelo menos, em princípio, não reforçam voluntariamente assimetrias territoriais pautadas em pressupostos exógenos, de competitividade territorial que distanciam os espaços concebidos do planejamento territorial daqueles espaços que definem a vida cotidiana e as demandas socioterritoriais na Amazônia. Para além das geometrias do desenvolvimento, desenhadas em polos, eixos e zonas, cabe pensar, assim, verdadeiramente, em novas geografias do desenvolvimento e em formas cívicas de ordenamento do território, que incluem o papel das cidades como condição de cidadania, e não como condição e meio de ratificar o desenvolvimento geográfico desigual.

\section{REFERÊNCIAS}

ABLAS, Luís Augusto de Queiroz. O "estudo dos eixos" como instrumento de planejamento regional. Regiões e cidades, cidades nas regiões: o desafio urbano-regional. GONÇALVES, Maria Flora; Brandão, Carlos Antônio; Galvão, Antônio Carlos Filgueira (Orgs.). São Paulo: Editora Unesp, 2003. p. 171-186.

ACSELRAD, Henri. Eixos de articulação territorial e sustentabilidade do desenvolvimento no Brasil. Rio de Janeiro: Projeto Brasil Sustentável e Democrático/FASE. 2001. BECKER, Bertha. Amazônia. São Paulo: Ática, 1990.

. Novos rumos da política regional: por um desenvolvimento sustentável da fronteira amazônica. In: BECKER, Bertha Koiffmann.; M IRANDA, Mariana. A geografia política do desenvolvimento sustentável. Rio de Janeiro: Editora UFRJ, 1997. p. 421444.

mond, 2006.

Amazônia: geopolítica na virada do III milênio. 2. ed. Rio de Janeiro: GaraBITOUN, Jan. Tipologia das cidades brasileiras e políticas territoriais: pistas para reflexão. In: BITOUN, Jan; MIRANDA, Lívia. (Orgs.). Desenvolvimento e cidades no Brasil: contribuições para o debate sobre as políticas territoriais. Recife: FASE, 2009. p. 1744.

BOUDEVILLE, Jacques R. Los espacios econômicos. Buenos Aires: Editorial Universitaria de Buenos Aires, 1969.

BRANDÃO, Carlos Antônio. Território e desenvolvimento: as múltiplas escalas entre 0 local e o global. Campinas: Editora da Unicamp, 2007. 
BRASIL. M inistério das M inas e Energia. Programa Grande Carajás. Brasília: M inistério das M inas e Energia, 1981.

. Presidência da República. Lei 9.276, de 9 de maio de 1996. Dispõe sobre 0 Plano Plurianual 1996 - 1999 e dá outras providências. Brasília: Presidência da República, 1996.

. Presidência da República. Lei 9.989, de 21 de julho de 2000. Dispõe sobre 0 Plano Plurianual para o período 2000 - 2003. Brasília: Presidência da República, 2000.

Presidência da República. Plano Amazônia Sustentável: diretrizes para o desenvolvimento sustentável da Amazônia Brasileira. Brasília: M M A, 2008.

Presidência da República. Macrozoneamento ecológico-econômico da Amazônia legal: Decreto 7.378, de 1으 de dezembro de 2010. Disponível em বttp://www.mma.gov.br/zeeamazonia>. Acesso: 5 jun. 2012.

CARVALHO, Maria Auxiliadora de; SILVA, César Roberto Leite. Economia internacional. 3. ed. São Paulo: Saraiva, 2006.

CORRÊA, Roberto Lobato. Região e organização espacial. 4. ed. São Paulo: Ática, 1991.

EGLER, Cláudio. Eixos nacionais de integração e desenvolvimento - impactos ambientais. Rio de Janeiro: CREA, 1999.

GALVÃO, Antônio Carlos Filgueira; BRANDÃO, Carlos Antônio. Fundamentos, motivações e limitações da proposta governamental dos Eixos Nacionais de Desenvolvimento e Integração. In: GONÇALVES, Maria Flora; BRANDÃO, Carlos Antônio; GALVÃO, Antônio Carlos (Orgs.). Regiões e cidades, cidades nas regiões: o desafio urbanoregional. São Paulo: Editora da UNESP, 2003. p. 187-205.

HARVEY, David. O novo imperialismo. São Paulo: Loyola, 2004.

. A produção capitalista do espaço. 2. ed. São Paulo: Annablume, 2006.

. Condição pós-moderna: uma pesquisa sobre as origens da mudança cultural. 20. ed. São Paulo: Loyola, 2010.

HUFFM ANN, Carolina et alii. Construindo centralidades cívicas: estratégias de articulação espacial e funcional. Buenos Aires, 2016. Disponível em: বttp:// www.archdaily.com.br/br/789014/construindo-centralidades-civicasestrategias-de-articulacao-espacial-e-funcional>. Acesso em: 02/07/2016.

IANNI, Octavio. Colonização e contra-reforma agrária na Amazônia. Petrópolis: Vozes, 1979.

KOHLHEPP, Gerd. Conflitos de interesse no ordenamento territorial da Amazônia brasileira. Revista Estudos Avançados, São Paulo, v. 16, n. 45, p. 37-61, 2002.

LEITÃO, Karina Oliveira. A dimensão territorial do Programa de Aceleração do Crescimento: um estudo sobre o PAC no Estado do Pará e o lugar que ele reserva à Amazônia no desenvolvimento do País. 2009. 285f. Tese (Doutorado em Arquitetura e Urbanismo) - Faculdade de Arquitetura e Urbanismo, Universidade de São Paulo, São Paulo, 2009. 
MADEIRA, Welbson do Vale. Modelos de desenvolvimento econômico e ordenamento territorial na Amazônia: rupturas e continuidades no corredor Açailândia-São Luís (MA). 2015. 236f. Tese (Doutorado em Desenvolvimento Socioambiental) - Programa de Pós-Graduação em Desenvolvimento Sustentável do Trópico Úmido, Núcleo de Altos Estudos Amazônicos, Universidade Federal do Pará, Belém, 2015. M ELLO, Neli Aparecida. Políticas territoriais na Amazônia. São Paulo: Annablume, 2006.

MELLO, Neli Aparecida de; THÉRY, Hervé. A armadura do espaço amazônico: eixos e zoneamentos. Revista Alceu, Rio de Janeiro, v.1, n. 2, p. 181-214, 2001.

NASSER, Bianca. Economia regional, desigualdade regional no Brasil e o estudo dos Eixos Nacionais de Integração e Desenvolvimento. Revista do BNDS, Rio de Janeiro, v. 7, n. 14, p. 145-178, 2000.

NEPSTAD, Daniel et alii Avança Brasil: os custos ambientais para a Amazônia. Belém: Gráfica e Editora Alves, 2000.

NORTH, Douglas. Teoria da localização e crescimento econômico regional. In: SCHWARTZM AN, Jacques (Org.). Economia regional: textos escolhidos. Belo Horizonte: CEDEPLAR, 1977. p. 333-343.

OLIVA, Aloizio Mercadante. As bases do novo desenvolvimentismo no Brasil: análise do governo Lula (2003-2010). 2010. 537f. Tese (Doutorado em Economia) - Instituto de Economia, Universidade de Campinas, São Paulo, 2010.

PERROUX, François. L'economie du XX' siècle. Paris: PUF, 1961.

. O conceito de polo de crescimento. In. SCHWARTZM AN, Jacques (Org.). Economia regional: textos escolhidos. Belo Horizonte: CEDEPLAR, 1977. p. 145-155.

PORTO-GONÇALVES, Carlo Walter. Amazônia, amazônias. São Paulo: Contexto, 2001. SANTOS, M ilton. Por uma geografia nova. São Paulo: Hucitec, 1980.

. O espaço do cidadão. São Paulo: Nobel, 1987. - A urbanização brasileira. São Paulo: Hucitec, 1993.

2008.

Espaço e método. 5. ed. São Paulo: Editora da Universidade de São Paulo,

SERRA, M aurício Aguiar; FERNÁNDEZ, Ramón García. Perspectivas de desenvolvimento da Amazônia: motivos para o otimismo e para o pessimismo. Economia e Sociedade, Campinas, v. 13, n. 2 (23), p. 107-131, jul./dez. 2004.

SM ITH, Neil. Desenvolvimento desigual: natureza, capital e a produção de espaço. Rio de Janeiro: Bertrand Brasil, 1988.

SUDAM. II Plano de Desenvolvimento da Amazônia (1975-1979). Belém: SUDAM, 1976.

Artigo recebido em 14 de julho de 2016.

Aprovado em 18 de julho de 2016. 